\title{
Craft as a Form of Mindful Inquiry
}

Louise Valentine, University of Dundee, UK, I.valentine@dundee.ac.uk

Georgina Follett, University of Dundee, UK

\begin{abstract}
In this research project 'Communication of Craft Practice' is the subject and the problem is one of transparency of the intellectual act and accessibility to the embodied knowledge. Why? The skill of coherently expressing the intellectual and personal voice within the development of craft practice is usually missing. There is a gap in our knowledge.

The methodological framework is Mindful Inquiry which is a synthesis of critical social science, hermeneutics, phenomenology and Buddhism (Bentz and Shapiro, 1998). The research involves working directly with professional practitioners to embark on a series of creative journeys from which craft as an experience, process, product and service could be observed and evaluated. The practitioners included a 3-D metal designer, curator, interactive jeweller, product artist and woven textile designer.
\end{abstract}

The aim is to reassess the term craft practice as a means of understanding the impact of social, political and technological change by documenting the practitioner's thinking processes throughout a period of practice. It is to consider combining visual and written outputs as means of supporting the identification of the new knowledge gained through practice, and how this knowledge is used cumulatively to develop craft. The objective is to nurture a dialogue with practice and to document the process of thinking and making associated with craft.

This paper provides the context and framework for research as well as presenting the findings from it. It exposes the methods and the accompanying rational for using them in relation to mindful inquiry, and it presents a new perspective from which to view and discuss craft practice. The argument is concerned with articulating the relevance of mindful inquiry as a methodology for critiquing and supporting the development of craft thereby supporting the contextual understanding and meaning of the research findings and procedures when they are presented. It is also to offer new craft knowledge in terms of the phrase 'practice'.

\section{Keywords}

craft practice, mindful inquiry, visual language, communication, methodology

\section{Introduction}

Mindful Inquiry is a synthesis of critical social science, hermeneutics, phenomenology and Buddhism. At the heart of this methodology is the concept of 'change' where perpetual activity is its inherent characteristic, both within the research context and of the subject under consideration, because the human condition is at the centre of investigation (Bentz and Shapiro, 1998). 
Buddhism permeates_Mindful Inquiry through the philosophy of mindfulness which is an awareness and understanding of one's own mind and how it influences one's perceptions and actions. The process and product of the discipline of mindfulness is inextricably interwoven: it is both a means and an end - a philosophy and a method (Valentine, 2003; Valentine and Ivey, 2009). The concept of 'postmodern chaos' and its presence in our everyday existence is a key reason for selecting Mindful Inquiry as an appropriate methodological framework to investigate contemporary notions of craft practice. The consequences of interdisciplinarity to the field of craft or the implications of modern high technology to methods and their associated aesthetics, for example, gives rise to a situation whereby traditional static frameworks for analysing and evaluating the applied arts can provide a distorted view of the realities of being a creative practitioner.

The person is placed at the centre of the process of inquiry in both a psychological sense_(for example, my personality style can shape my research method) and a philosophical sense (in that research is viewed as an embodied programme of activity, a way in which I engage with the world). The premise of Bentz and Shapiro's concept of Mindful Inquiry is the idea that research is intimately linked with the researcher's awareness of his/her life and his/her lifeworld. ${ }^{1}$ They advocate that 'awareness and reflection on your world and the intellectual awareness and reflection that are woven into your research affect - or should affect - one another' (Bentz and Shapiro, 1998:5). Mindful Inquiry is a reciprocal system: quality research contributes to personal development as a mindful practitioner and personal development, in terms of awareness and reflection, embodies the research. It sits within the realm of 'reflective practitioners' where the researchers do not adopt a detached and impersonal approach rather they have direct engagement and involvement._In this investigation 'Communication of Craft Practice' is the research subject and the problem is one of transparency of the intellectual act and accessibility to the embodied knowledge. Why? The skill of coherently expressing the intellectual and personal voice within the development of craft practice is usually missing. There is a gap in our knowledge. ${ }^{2}$

On reflection of the intellectual and social meanings of craft practice, craft is often misunderstood as skilful making. The notion of craft as a concern for innovation, individual vision and future cultural concerns: a fusion of art, science, engineering, and technology, is uncommon. The misconception of 'craft as skilful making' fails to address the maker's capacity to synthesise and integrate information. While recent texts (for example the work of Glenn Adamson, Howard Risatti and Richard Sennett ${ }^{3,4,5}$ ) have gone some way to redress the imbalance in understanding the intellectual_value of craft, the plethora of literature which services crafts as a hobbyist pursuit remains uppermost in the minds of popular culture.

In Mindful Inquiry, the researcher's ways of engaging with ideas, data, methodologies and decisions are a critical consideration and as such, it is pertinent to pause and present what they are to this study. My environment for learning is design and $\mathrm{I}^{6}$ understand design as a dialogue,

an activity that requires a freedom to explore, to allow imagination and creativity to range widely and bring knowledge and expertise alive in a 
wild uninhibited dance. It is a process that involves looking, listening and thinking, allowing collective thoughts to levitate: to sit suspended in the mind and to be given space, through time, to develop as the process of creation unfolds (Valentine, 2004:15).

This suspension of thought allows a pattern to evolve, providing an individual with a picture, which depicts the interrelationship(s) between different and often contrasting elements of an idea. Subsequently, the lens with which I view_Mindful Inquiry is design and the context for developing design is_Mindful Inquiry.

Adopting Mindful Inquiry for this investigation is used as a means of generating and contributing to social knowledge of craft practice, thereby complementing the existing cultural, material, product and technical knowledge._Mindful Inquiry was used to embark upon a journey into the context and culture of contemporary practice. The journey asks questions of how the mind's eye synthesises visual, oral, sensory and written information, and the process by which ideas are transposed into an individual's personal philosophy.

\section{Mindful Learning}

The cognitive aspects of mindfulness, as adopted by Hanh (1991), Kabat-Zinn (1994), | Langer (1989, 1997) and,_Bentz and Shapiro (1998) are that it is a way of seeing which causes and maintains inter-connections. It is an approach to inquiry that draws a person's attention and awareness to the impermanence and uncertainty surrounding a problem. Much of the learning associated with Mindful Inquiry is social learning; learning about language and social convention rather than methods, and it is a requirement of the inquirer to become socialised into a community. The inquirer's remit includes learning where the action is and becoming an active member of the community (Bentz and Shapiro, 1998).

This process of socialisation and familiarisation for this study of craft took place throughout the research but was intensively invested in within the first two years (of the five year project), attending national exhibitions, museums and trade fairs, meetings with national agencies and champions of craft within Scotland, England and Ireland ${ }^{7,8,9}$. Indepth conversations about craft as a practice and methodology were held at regular intervals with the jeweller Georgina Follett. ${ }^{10}$. The process also took the form of an international conference and exhibition entitled 'New Craft: Future Voices'11 and 'Future Voices: Celebrating Diversity' organised by the authors.

The process and output of these events were a fundamental aspect of the social learning perspective. Taking place over an 18-month period (including pre and post event responsibilities), it offered the researcher deep insight into the intellectual dialogues that go with craft practice; the multiple forms of craft; the range of traditional and digital methods currently being employed; awareness of the material, technological and cultural aesthetics of craft practice; the alternative ways of approaching 
collaborative and interdisciplinary frameworks; the various ways people discuss and emphasise craft and, the visual impact of craft research as a new form of craft practice.

The 'Future Voices: Celebrating Diversity' exhibition provided the opportunity to view a broad range of craft practice from different cultures (in terms of academic cultures of inquiry or research frameworks and, cultures associated with native or societal heritage eg Australasian, Canadian, Nordic). The exhibition also offered the opportunity to view craft practice across a bandwidth of material specialisms (eg ceramics, jewellery, interactive jewellery, metalwork, printed textiles, woven textiles). It presented a visual discourse and offered a way of distinguishing between traditional and non-traditional forms and, historical and contemporary aesthetics. For example, the work of Carol Epp (Figure 1) exposed a traditional perspective in terms of the form and aesthetic, while the work of Sarah Kettley (Figure 2) presented a non-traditional example of form and aesthetic. Epp's work is concerned with refining the form and function through subtle shifts in technique and, the concept underpinning the work (ie that of a vessel) is in the tradition of ceramics. Kettley's work on the other hand, is a non-traditional form of jewellery and as such, challenges the traditional concept of jewellery. While the conceptual underpinning of her work is very good (ie wearable computing infused with soundscapes), the relation between final form and concept is oblique.

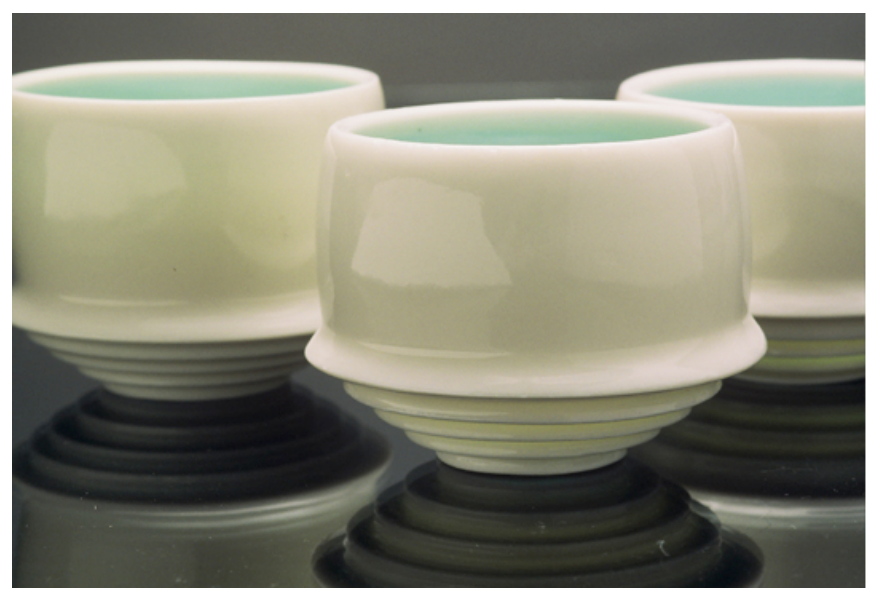

Figure 1: The ceramic work of Canadian craft practitioner Carol Epp 


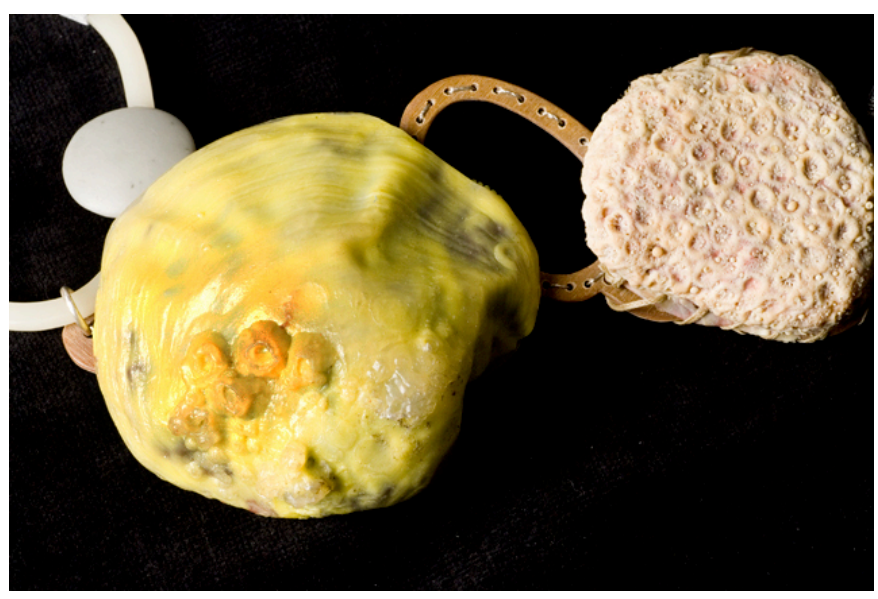

Figure 2: The interactive jewellery of Scottish craft practitioner researcher Sarah Kettley

The collection of exhibits facilitated understanding of a subtle but important delineation, in that a traditional form (for example, a ring or neckpiece in the context of jewellery) does not indicate a lack of innovation in terms of concept and aesthetic. And, that a historical or cultural aesthetic within a traditional form does not indicate there is no radical thinking underpinning the craft. For example, in the work of Barbara Jardine (Figure 3) whose jewellery exposes a strong Trinidadian cultural aesthetic through a traditional form, the intellect is found through the interrelation between the material elements of metal, stones, amber, black coral, ivory, beetle carapaces and tortoise shell. The visual experimentation and high level of craftsmanship used to bring the array of materials together is where the intellect is embedded and, where the level of risk and innovation can be measured. The value of this observation of practice was that great care must be taken when evaluating craft in terms of the aesthetic (where aesthetic is the intellect). It also indirectly raised an issue with the use of language when looking at craft as an intellectual inquiry, specifically in the application of familiar terms or categories of form such as 'traditional' and 'non-traditional'. If innovation and radical thinking can be found in traditional forms employing a historical aesthetic, then mindfulness must be adopted when observing craft that employs contemporary materials and new, advanced technologies to achieve unusual forms: one cannot assume innovation exists within craft because it exposes an unusual form or applies new techniques and/or technologies to create an aesthetic. 


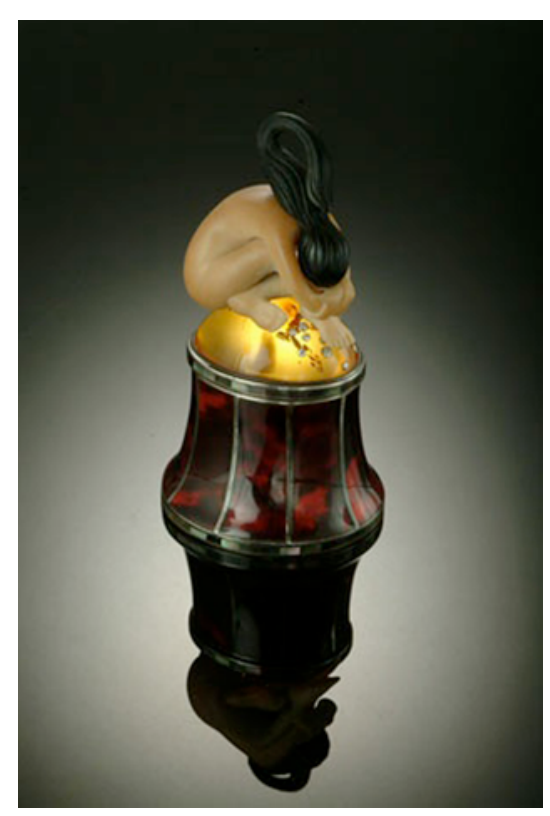

Figure 3: 'Heigh Ho' is an example of the intellectual and visual voice of Trinidadian jeweller Barbara Jardine.

'Future Voices: Celebrating Diversity' evidenced (amongst other issues) differentiation of craft aesthetic specifically in terms of technological, material and cultural-led aesthetics and, the myriad forms of craft that result from the interplay between technology, material and culture. It indicated that craft research is having a positive impact on contemporary developments, influencing thinking and the quality of product in terms of a new aesthetic of 'captured time', for example the work of Gillian Bunce, Drummond Masterton and Hazel White. It was observed that technological pathways also act as_a progenerator of works, achieving aesthetic qualities previously unattainable through traditional skills, materials and techniques (see for example, the works of $J \mathrm{R}$ Campbell and Tara Carrigy in Figures 4 and 5). These works embrace the human body as part of their aesthetic with interaction as the aesthetic, moving the tradition of the automaton ${ }^{12}$ further forward. The exhibition raised a number of questions, including: when craft knowledge is used in the production of a visual object, can the object be framed as craft? Are historical frames of reference appropriate when evaluating the aesthetic impact of modern technologies on postmodern craft? Is twenty-first-century craft an ethos embedded in the maker rather than being embodied in an end product of making? How can we evaluate the aesthetic of postmodern craft? 

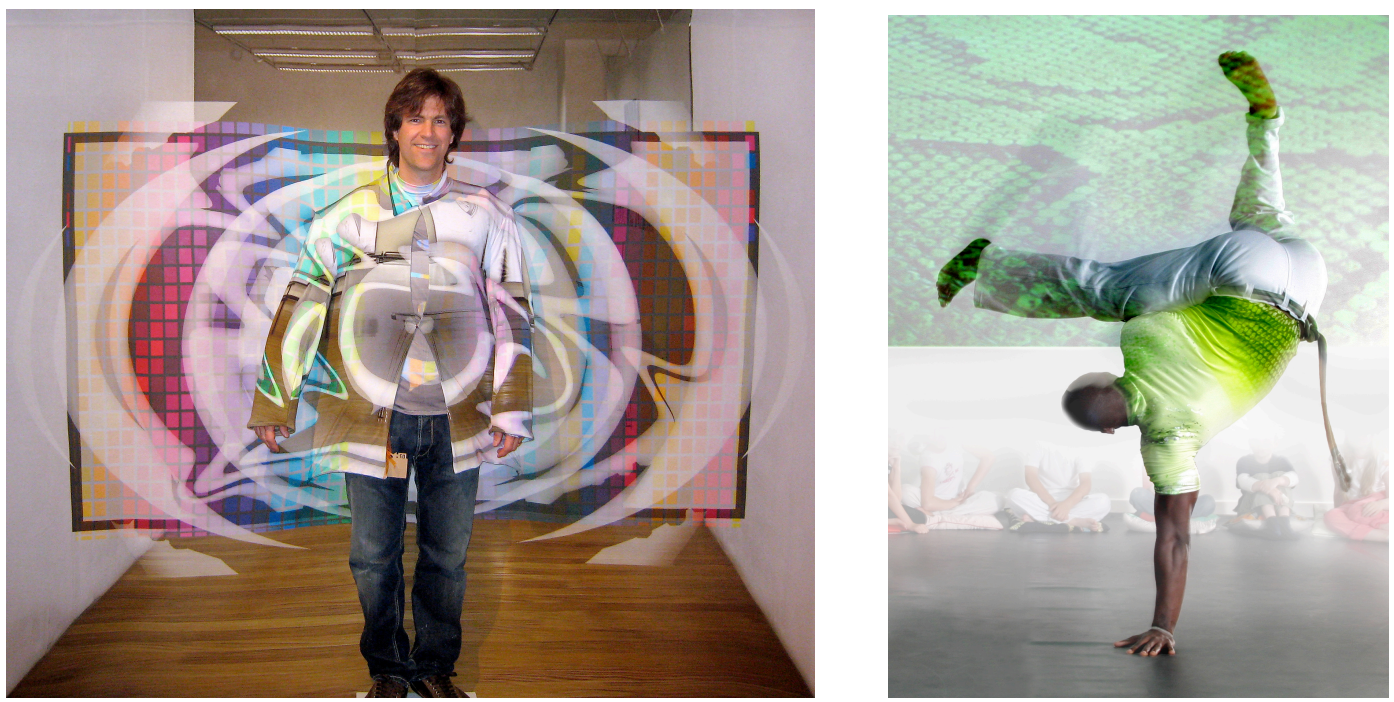

Figure 4 (left) $J$ R Campbell's 'Wearing this Distorted Image' and Figure 5 (right): Tara Carrigy's 'Adaptive Craft'. The aesthetic lies in level, form and sophistication of interactivity between object, viewer and environment, which has been facilitated by advanced technologies and, in the case of Carrigy within an interdisciplinary context involving scientists, musicians, dancers and engineers.

The exhibition and its associated international peer review process of selection provided the platform for identifying and commissioning five practitioners to engage formally with the 'Past, Present and Future Craft Practice' project and create new works. The following practitioners were selected: Hazel White (Figure 6), interactive jeweller and conceptual thinker Tim Parry-Williams (Figure 7), a textile designer working from a depth of understanding of the nature of textile material Geoffrey Mann (Figure 8) whose work is concerned with capturing the transient through the use of new technologies; Sally Moir (Figure 9), curator with the ability to conceptualise space and, Drummond Masterton (Figure 10), silversmith using a reductionist approach to product development. They are all mid-career and have an acknowledged reputation for their work in the UK. Selection was made on the basis that the work demonstrated a strong visual aesthetic or indexical mark, had clarity of purpose and was articulate in discussing and revealing conceptual thinking. 

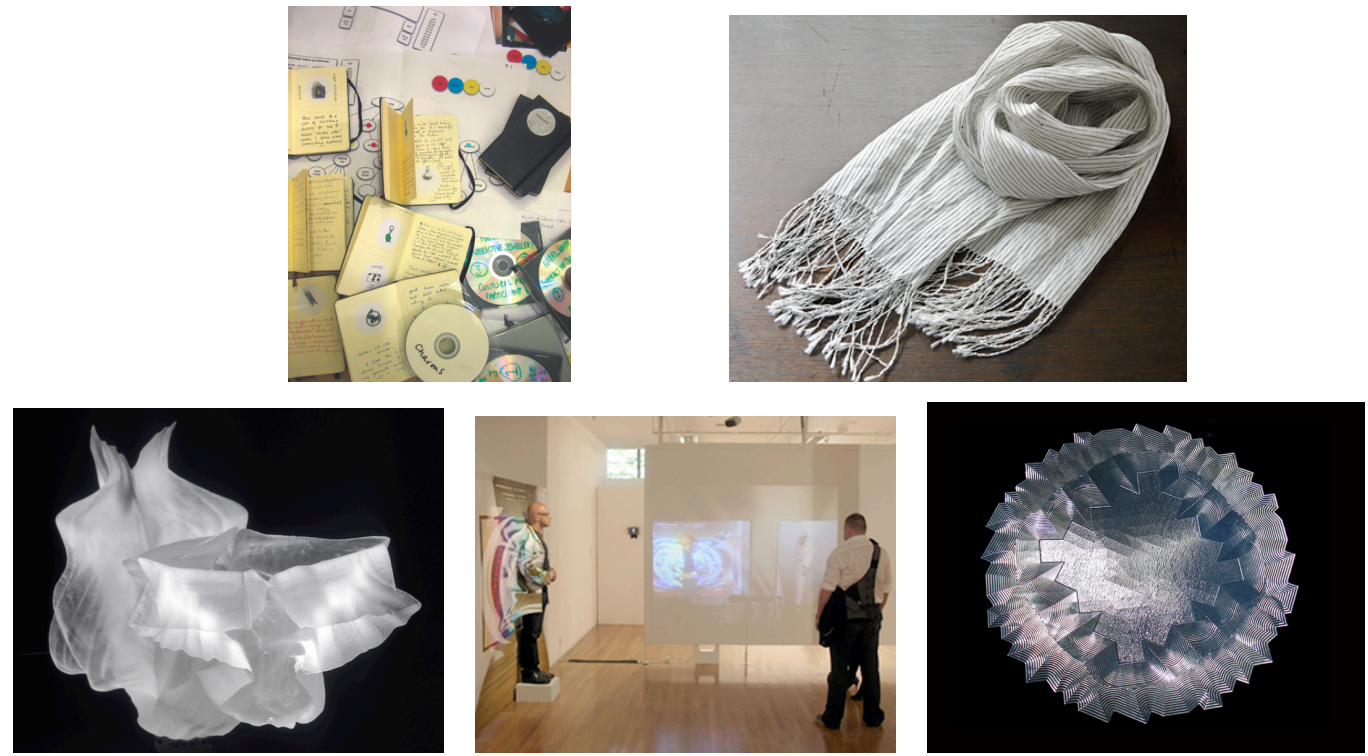

Figure 6 (top left): 'Charmed' process image by Hazel White and, Figure 7 (top right) Handwoven textile by Tim Parry-Williams. Figure 8 (bottom left) 'Flight' by Geoffrey Mann, Figure 9 (bottom middle) Sally Moir, section of her New Craft Future Voices curatorial strategy. Figure 10 (bottom left): An example of Drummond Masterton's_craft.

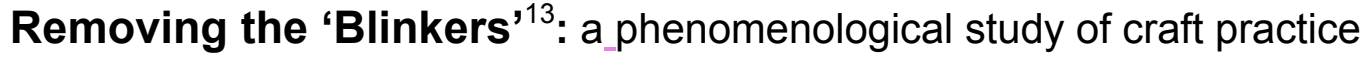

Phenomenology is a school of philosophy that focuses on the description of consciousness and of objects and the world as perceived by consciousness ... [It attempts to take seriously the fact] that we know we are conscious beings and that everything we know is something we know only in and through consciousness... A primary focus of phenomenology has been to get ourselves out of everything we take for granted about the world and about ourselves through 'bracketing'... [a process] that sets aside aspects of a situation in order to focus full attention on other aspects of it (Bentz and Shapiro, 1998, p.40-41).

In terms of this research, the culture of inquiry helped me to look at the phenomenon that is craft practice by 'bracketing' the everyday definition of 'craft practice'. It was the means with which to reconsider it as a final product or object, in order to focus fully on the experience, process, product, and service aspects. I looked at craft practice from this collective perspective by creating a ten-year map of an individual's 'lifeworld' (Figure 11 ), rather than drawing a chronological portfolio of the production of single objects (Figure 12). This perspective is of craft as a lifework, an ethos developed through time where technique, attitude and behaviour evolve through, and emerge within, a mixture of life experiences, for example, behavioural tendencies, educational background and cultural engagement activities. I also created a series of creative, critical writings as a means of familiarising myself with the different modes of craft practice and as a vehicle for evaluating the extended conversations with the practitioners. 
This notion of 'lifeworld' in the context of craft is referred to as a 'cultural enrichment cycle' (by the lead researcher) whereby craft practice is understood to be a constantly moving and continually growing process, with embedded layers of meaning and experience. It is considered in terms of layers of activities, running concurrently through the everyday life of an individual craft maker, rather than a solid 'block' of unrelated events or projects. This viewpoint is understood to be one way in which this work contributes to craft knowledge as many existing historical and theoretical contributions favour interpretation of craft practice as a finished object(s) disassociated from the deep personal tendencies and individual values of the maker.

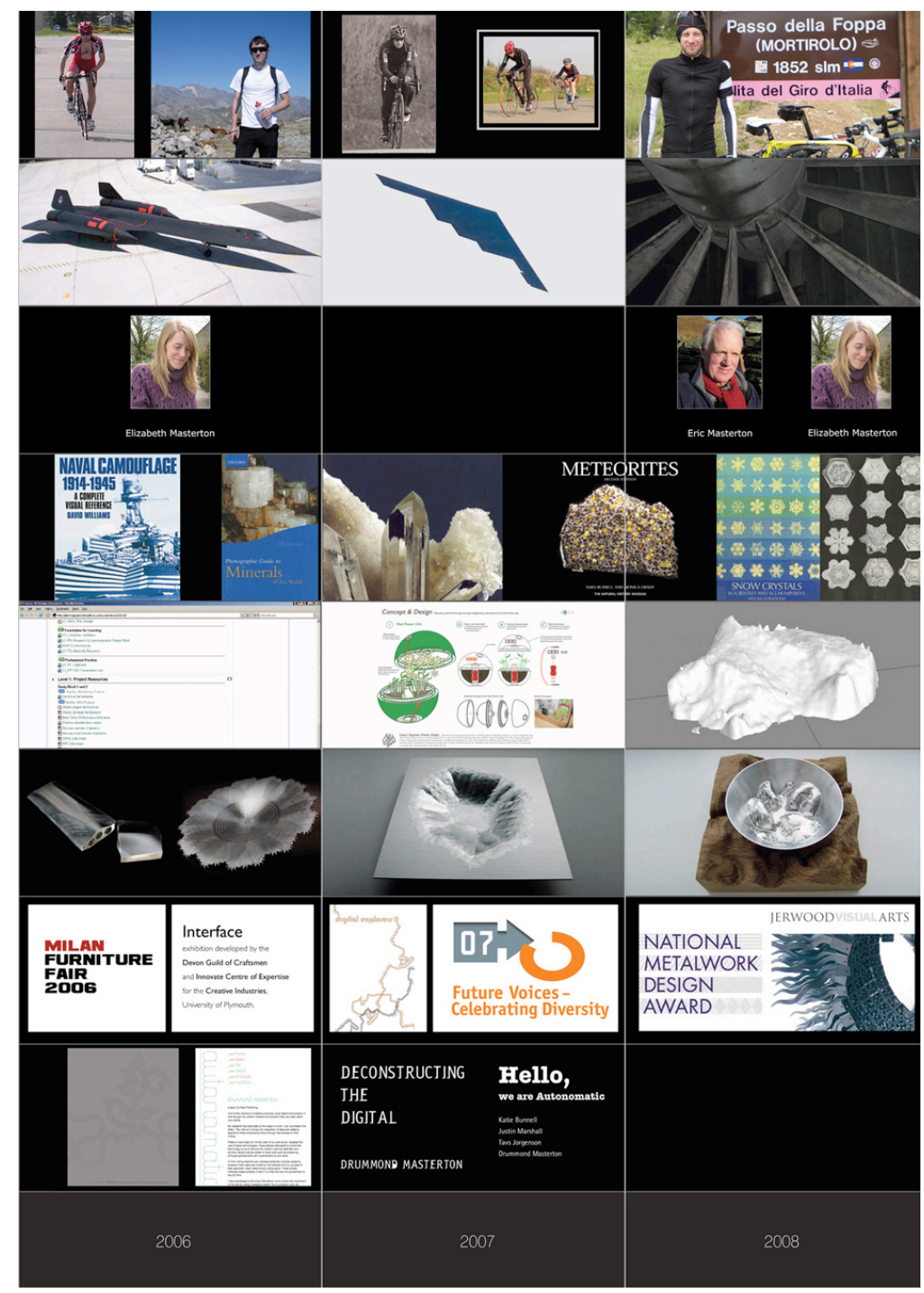

Figure 11: A snapshot of (three years out of the ten year) visualisation map or 'cultural enrichment cycle' for Drummond Masterton, created by the lead author, offering an alternative viewpoint from which to understand the term 'craft practice'. From top to bottom, the concurrent layers of activity that constitute 'craft practice' for Drummond are cycle racing, developing knowledge of military modes of transport, (specifically aeroplanes and submarines - their form and nature), people who influence his thinking, reading of books concerned with mathematical structures and visual forms such as crystals and meteorites, teaching 3D design, crafting objects, exhibition participation and academic writing. 


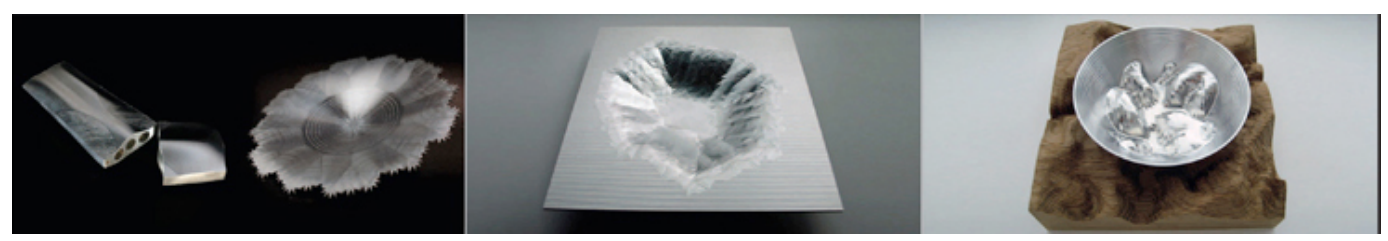

Figure 12: A snapshot of objects from the 'cultural enrichment cycle' for Drummond Masterton, representing three out of ten years of craft practice.

Phenomenology is very useful for noticing what things we take for granted and it encourages us to see things in a new way, to step outside of our culture and question our habitual ways of describing and defining things. In this respect it is part of mindfulness. In a world where the concept of 'change' is a given and technological progress pervades our everyday existence, this viewpoint was deemed appropriate as it supports the need for questioning basic assumptions about the concept of 'making' craft, and a reappraisal of the question, 'What is craft practice?'

The 'cultural enrichment cycle' as craft practice was questioned directly and indirectly via extended conversations with the practitioners. I paid attention to the phenomena being investigated by writing a deep phenomenological description of my own experience of craft practice: my experience of the craft of five practitioners and extended conversation with them about their practice. What was their way of experiencing craft practice? As human phenomena, what does craft practice mean from the perspective of an individual maker?

In this study, I am the instrument of articulation and to become this I developed deep empathy with the concept and practice of craft through observation and extended conversation with contemporary practitioners. As Bentz and Shapiro (1998:97) note, '[t]he primary tool of the phenomenologist is the inquirer's own consciousness'.

I am not the subject. In my preparation for working with the research participants, I immersed myself in experience that matches the participants. I continued nurturing my lifeworld and reflecting on the development of my 'cultural enrichment cycle'. I engaged in the creation of new work (which in my practice is visualisation through interactive media) and I taught design and practice-led research to a range of undergraduate and postgraduate art and design students. I daily discussed the business of design and the practice of creativity with my partner (a design consultant). I wrote and I nurtured my network by engaging in a series of new activities (such as novel research projects) and conversation about craft, design and the future of education for the creative industries. In doing so, I created in-dwelling awareness.

What is important to note about this phenomenological study of craft practice is that the process brought into awareness and made use of my 'Grasshopper' tendencies. What do I mean by 'Grasshopper? I mean my propensity to see opportunities all day, everyday and to pursue the subconscious idea that shines brightest or speaks loudest. 
The rhythm of my hopping and jumping does not always make sense, sometimes it can appear that too much is going on at one time and at other times, it can look as if I have gone off at a tangent for no apparent reason! The important aspect is the random movement; this movement is a way of evaluating, it provides necessary time and space to test new ideas and talk to different people. It creates an intellectual freedom to look at work from different points of view and, perhaps most importantly, it keeps my mind active. The other thing that my 'grasshopper' strategy helps to manage is a tendency to want everything to be perfect. This characteristic is with me in all that I undertake, but through this study I realise that it is balanced by the inherent inability to give full attention to one study or project - a mixture of small and large, complex and complicated. It is also distinctly possible that it is the perfectionist in me that brings out the 'grasshopper' rather than the other way round!

In this research, the implications of 'grasshopper' were that my engagement with the 3D metalworker, curator, jeweller, product artist and woven textile designer were mixed together as one collective process, where conversations, interviews, observations, workshops, writing and visualisation activities flowed in and out of awareness. Attention was given to all of them and none of them and reflection on small pieces of information was made in parallel with reflection on the entire Mindful Inquiry framework.

It is important to highlight that while I present this work by writing in first person rather than third person (which is the convention for much scientific research), it does not devalue it, or imply that it is detached from the real world. A critical attribute of phenomenology is the ability to provide rich descriptions of the phenomena and the ability not to approach discourse analysis through a mechanistic manner of interview, transcribe and thematic identification. As Bentz and Shapiro (1998:104) note:

[T]o believe that phenomenology is focused primarily on the personal experience of the researcher and her subjects or on subjective experience cut off from the real world is a mistake. Although phenomenology may focus on personal experience, one of its primary goals is to understand the real world. It simply recognises that the real world is given to us in consciousness.

\section{The Hermeneutic Dimension: interpretation of and for craft practice}

The interpretation of texts or the theory of interpretation and understanding is the basic premise of hermeneutics. This view, note Bentz and Shapiro (1998: 40) was extended by Martin Heidegger,

into a general approach to our understanding of our existence and Being in general....[Indeed, h]ermeneutics emphasises that all our understanding and interpretation are bound to, and shaped by, our existing in a particular historical and cultural context, because we use the concepts, language, symbols and meanings of our time to interpret everything. Therefore hermeneutics involves us in perpetual asking, of anything meaningful that we study as well as ourselves, 'Where are you coming from?' 
Interpretation has a divergent nature; it is methodologically open-ended and ambiguous. In this sense, it can be directly linked with theories of design where indeterminacy is a key tenet and the activity of rhetoric (as both a language and a metalanguage) is a core element in a designer's thinking (Buchanan, 1995; Cross, 1999; Valentine, 2001 and 2004). Subsequently, there are two contradictory elements to the hermeneutic analysis for this study which must be acknowledged - one is that a heightened level of ability and understanding of ambiguity has been achieved by the lead author through her 17 years of design studies, yet, this interpretive ability and viewpoint may cloud her judgement when analysing the texts gained through extended conversation and observation with the five contemporary craft practitioners. However, this realisation of a potential prejudice is one of the values of hermeneutic analysis as Bentz and Shapiro (1998: 114) note, 'The hermeneutic encounter is one that, when done mindfully, prompts the interpreter to reflect on her prejudices, understand them, attempt to justify them as rationally as possible, and go beyond them through what is encountered.'

In this study, hermeneutics is blended with phenomenology to provide contextual awareness and perspective, where narrative, specifically the method of storytelling, is used to identify the theoretical underpinning of an individual's craft practice by analysing his/her craft practice through visualisation and extended conversation. It is also used to nurture understanding of the meaning of craft practice in modern society. The stories are the rich descriptive texts created as part of the phenomenological perspective of this Mindful Inquiry. The texts are both an outcome of interpretation and a basis for further interpretation. They denote a level of understanding about craft practice when read as individual pieces and as a collective body, and they also form the basis for further interpretation.

The stories exposed craft practice as a meditative act requiring mental and physical distance during the decision-making process, yet a constant, intimate relationship with the idea. They revealed craft practice as a pursuit of personal and professional 'identity': a means of realising and recognising the concept of 'self'. It was unveiled as a social activity, a dynamic network of conversations with people, places, memories, ideas, objects, fact and fiction - both in time and through time ie conversation(s) with people in real time, mixed with conversation(s) with the self about past experiences and knowledge. Craft practice was understood to be a fascination, indeed an obsession with developing their own visual language or indexical mark, where experimentation and risk taking were central tenets and the essence of the term 'making'.

The stories offered insight into the personal need to achieve excellence and seek approval - sometimes from the external world and sometimes from themselves, sometimes only from themselves. There was an intuitive need to clarify the value of their ideas in the context of culture through exhibition(s), awards, lecture(s) and workshop(s). There was also a business need to secure financial investment through these same aforementioned activities. 
They provided insight into how individuals create the questions with which to challenge the idea. They revealed that the practitioners all looked for rhythmic activities, and constructed meditative spaces in different ways to suit their lifestyles in order to internally resolve issues within their making practice. The interactive jeweller's rhythm was found in the way she engaged people within her thinking process; her craft is a social product. She carried the most recent prototype with her at all times and used the interstitial moments in her day to unwittingly inform colleagues of her new work and seek their immediate reaction, using this to inform her questioning and decision-making. The silversmith's rhythm was found through the solitary pursuit and physical challenge of cycling/cycle racing which was used as a means of resolving 'tension' in his craft practice, often riding for hours at a time to understand the intellectual conflict hindering progress; his craft is a meditative product. The woven textile designer's intimate relationship with material (fibres, structures and finishes) coupled with his audacious and poetic personality was the home for his rhythm; his craft is also a social product. His affinity with the cultural ethos of Japan significantly influenced his thought process, especially his efforts to achieve a holistic approach and a balance between tradition and modernity. The curator's social relation with object (be it art, craft or design) and the insatiable need to take the object to new audiences is where we found her rhythm; her craft is also a social product. The speed with which she conceives and transposes her visions from two-dimensional abstract forms to three-dimensional tangible environments and, the manner in which she communicates with her team and artists is where we find the intellect and decision-making. In a similar way, the ceramic and glass artist is also audience driven, and the rhythm of his practice was tied to the pursuit of identity through international acknowledgement, which stimulates his new product cycle; his craft is both a social and political product.

The stories revealed physical making $\underline{i e}$ the application of techniques and hand skills, as a small proportion of the craft practice process as they exposed a large repertoire of activities, personal traits and personal histories that impact on their craft. The stories described the rhetorical act of craft practice by exposing the myriad of interrelated activities that exist within the process, irrespective of the material or technology employed to physically expose the idea and transpose it into a tangible object. In doing so, they exposed craft practice as a personal journey conducted through life, where a heightened, proficient and eloquent use of the visual language is developed and used to question and resolve a concept.

It is important to draw attention to the fact that hermeneutic inquiry is not a free-reign approach to analysing text but a mindful quest for objective understanding through interpretation. It is founded in the belief that the researcher cannot escape from being involved in the context of explaining which naturally encroaches on the context of the data. This is the 'nub' or the heart of the challenge for the researcher, in that close proximity,

is both the problem of validation and the basis for validation. The researcher's job is to bring to bear on the data all he knows about his present context in order to understand the context of the data. For in the long run the validation is the ability to make sense of the relations between the two contexts. (Bentz and Shapiro, 1998:112) 


\section{Craft Practice}

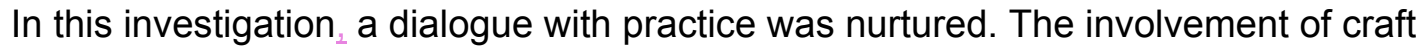
practitioners was seen as a fundamental tenet of the research project, in that the voice of practice is missing in large part from literature on crafts. The assumption underpinning this was that viewing contemporary craft practice from the practitioner perspective would enable primary knowledge and give clarity to the way in which craft was advancing and evolving within contemporary visual culture.

The research sought to understand the development of a craft practitioner's personal journey, of how they gain inspiration and what drives them to develop their work, whether it is developed on the visual, conceptual, material or technical basis. In order to understand an individual's development the research looked at recent practice to understand whether the journey is linear, moving in a forward direction, laterally or backwards. To facilitate this understanding visual timelines were constructed from final product/objects and personal influences including literature, travel, teaching, sport and related creative practices, such as writing and exhibiting. This visual mapping allowed

for an evaluation of patterns of productivity, from which an individual's development can be extrapolated and compared in order to understand whether craft practice operates a universal model, or whether it is idiosyncratic in form and dependent on many variables.

Given the rationale for selection it may be possible to understand that different individual imperatives require specific circumstances for craft to operate within, and to develop an understanding of which particular environments allow for the greatest progress to be made, collectively and individually.

The visual timelines and stories encapsulate the working life and environmental constructs used by the practitioners in the formation of their work. The model has the potential to act as a developmental tool for ongoing use by practitioners to enable them to understand the generative circumstances under which they operate most effectively, and how they operate within certain patterns, and what effect apparent disparate and unconnected elements have on their practice.

Outcomes of 'Mindful Inquiry' were constructed through stories and ten-year visualisation maps of each practitioner's journey of practice. The assumption of craft as a lifetime journey means the ten-year snapshot was the shortest timeframe possible to give coherence to the practice of the practitioner, and allow an understanding of the patterns of an individual's progress and the constituent parts of their practice. Mindful Inquiry of Craft Practice through the work of the four practitioners all showed different patterns and the visualisation maps identified rhythms within practice revealing progress. However, ten years was too short a timeframe to gain a full sense of these; a timeframe of 15 years would allow for verification of the working processes and practices. The maps identified the progress of skill, intellect, content and knowledge; understanding progress within practice, not through singular objects, but as a holistic journey. The maps or pictograms evidenced that intellectual skill developed in the work of all the practitioners, as did knowledge of material and technique, people and culture. And, the ability of the practitioners to develop self-knowledge directly impacted on the levels of innovation within their practice. 
Craft research has a value to craft practitioners, demonstrated through taking a research methodology and applying it to support understanding of both practice and research.

On reviewing the research process and outcomes, it is acknowledged that they offer a basis to undertake a SWOT analysis of the individual's practice to understand the different layers of activity that makes up their practice. The visualisation will allow for an individual evaluation of the impact of the different elements of their life journey on their work; providing an insight into different aspects and their direct effects on practice, through research, intensive engagement, volume of work and their management within it. Potentially the practitioner could alter these relationships within their portfolio, rebalancing and influencing potential impact thus perhaps driving innovation at a faster pace than their current practices.

The model offers an understanding of craft practice as layers of a journey of the self, which influence how an individual moves forward; it is the self that requires understanding as a practitioner/researcher with layers of activity rather than through an outcome or output.

The ten-year snapshot is the shortest timeframe possible to give coherence. The authors believe a 15-year timeframe would allow for verification of the progress of skill, intellect, and understanding progress within practice as a journey. This further research will need to be undertaken through revisiting the practitioners within a five-year window.

The 'Mindful Inquiry' model revealed that all the practitioners developed their intellectual skill, knowledge of material and technique, people and culture: they also enhanced their ability to develop their self-knowledge to increase the level of innovation within their practice.

In order to make this model universal Valentine will develop a series of self-reflective questions along with a pro forma for practitioners to place the essential elements that make up their journey, which embodies the elements of practice. This will offer individuals an understanding of craft practice as layers of a self-directed journey.

\section{Endnotes}

${ }^{1}$ A 'lifeworld' is essentially 'the world of everyday life'. In this research, the lead author's life is situated within the field of design, having trained as a printed textiles designer and developed her visual thinking through interactive media over the past decade. Richard Buchanan's philosophy of design has shaped her knowledge of design and her understanding of its role within contemporary society and culture. Buchanan's work emphasises the rhetorical dimension of design thinking and is discussed in the context of the liberal arts. He articulates design as both a language and a metalanguage.

2 The ideas underpinning this study were initially articulated by the authors in the original Arts and Humanities Research Council (UK) grant application proposal, 'Past, Present and Future Craft Practice: an investigation into the relation between skill, intent and culture'. For further information, visit www.futurecraft.dundee.ac.uk. [Accessed May 2010] 
${ }^{3}$ Glenn Adamson's Thinking Through Craft (published by Berg in 2007) explores historical and contemporary ideas surrounding 'craft' His examination offers a range of historical, critical and cultural perspectives, giving insight into the instrumental space that craft occupies in contemporary art. In his book Adamson discusses, for example, craft as an altered currency in today's visual lexicon, he examines attitude between art and craft, provides a forum for 'thinking though craft' and what such thinking might entail and he considers the finished work (be it art, craft or design) as supplemental to the underlying concept. He does not seek or provide definitive answers. This in itself is a useful and much needed contribution to the field.

${ }^{4}$ A Theory of Craft: Function and Aesthetic Expression (published by The University of North Carolina Press, 2007 and written) by Howard Risatti addresses one of the most persistent issues in craft; that of craft's relationship to fine art. As discussed in the introduction, the process of 'intellectualising' art - from the Renaissance humanists to the present day - has no parallel to date in the craft field. This lack of an equal theoretical framework has cast craft in a negative light and it is this imbalance that Risatti addresses by providing a new formal theory of craft. The abiding theme of the text is the notion of craft and the crafted object: what distinguishes a 'craft' object from a 'fine art' object? Can craft objects be considered 'art' objects at all? What is the difference between functional objects and 'art' objects and does craft's symbiosis with making, use and function preclude the label of 'art' at all? Rather than seeing craft as a traditional practice which is unconcerned with the challenges posed by modern industrial production or an area of practice, which should be allowed to dissipate into 'fine art', Risatti argues for a theory grounded in craft's own distinguishing features; not a theory imported from elsewhere and adapted to fit.

${ }^{5}$ Richard Sennett's The Craftsman (published by Allen Lane in 2008) examines the articulation of technique, and is viewed from the social context of material culture rather than a visual arts perspective. In this first volume (of a potential three) the author addresses the theme of craftsmanship and the portfolio of mental and physical skills required to do something well, for its own sake. Sennett draws upon diverse facets of society to illustrate this, citing examples ranging from parenting to computer programming. By using an eclectic range of illustrations, he broadens the parameters of what constitutes craft thus introducing a new concept, which one might describe as 'social craft'. Sennett's earlier career was that of a cellist and his understanding of the sensitivity and craft of music greatly informs his writing. The Craftsman is split into three parts (Craftsmen, Craft and Craftsmanship), and each section addresses elements that constitute the mix of skills required for the dialogue that exists between mind, body and materials.

6 'I' denotes the lead author

${ }^{7}$ Examples of the trade fair events include 'Collect' (2006 and 2007 at the Victoria and Albert Museum [V\&A], London) and 'Showcase' (2006, Crafts Council of Ireland, Dublin). Exhibitions included 'International Arts \& Craft' (2005, V\&A Museum, London); 'Black Mountain College' (2006, Oxford); 'Beauty \& Japan', (2006, British Museum), Out of the Ordinary: Spectacular Craft' (2007, V\&A Museum, London), 'Cutting Edge Craft' (2007, National Museums Scotland, Edinburgh); 'Memory and Touch' Symposium (2008, Royal Institute of Architects, London). 
${ }^{8}$ National agency meetings included one with Dr Helen Bennett, (the then Director of the Crafts Division), the Scottish Arts Council; Professor Stuart MacDonald, (the then Director of) The Lighthouse, Glasgow; Ms Rosy Greenlees, Director of the Crafts Council, London; Mr Leslie Reed, (the then Chief Executive of), Crafts Council of Ireland (1994_2006) and Ms Rose Watban, Senior Curator of Applied Arts Collections, National Museums Scotland, Edinburgh.

${ }^{9}$ The lead author organised a series of talks, inviting craft champions to visit Dundee and discuss their work with the research team and their colleagues. Examples include: the silversmith Michael Lloyd the Scottish craft historian, Elizabeth Cumming; interactive jeweller Jayne Wallace and curator Amanda Game. For further information, visit www.futurecraft.dundee.ac.uk

${ }^{10}$ Professor Georgina Follett is the Principal Investigator of the 'Past, Present and Future Craft Practice' research project. She is a craftsperson with over 30 years' experience in the field of 'plique-à-jour' enamelling. Producing pieces of high aesthetic value, Professor Follett's work has been exhibited widely including the jewellery gallery of the Victoria and Albert Museum, where examples of her work are on display in their collection.

11 'New Craft: Future Voices' was a three-day event with 45-refereed papers and five keynote speakers. There were 125 delegates from 14 countries and the 'Future Voices: Celebrating Diversity' exhibition showcased 27 projects and over 250 pieces of work from eleven countries. The rational and content for the international conference 'New Craft Future Voices' can be viewed at www.newcraftfuturevoices.com. (Accessed 12 January, 2010)

12 'Automoton' is a machine with a hidden or clockwork control that makes it move.

13 'Blinkers' or 'blinkered' refers to narrow-mindedness and a restricted view. It implies the ability to see only what is directly in front of you when moving forward, closed-off from seeing what is at either side of or behind you when engaged in a journey. It is a term of reference derived from working with horses where 'blinkers' were put on a horse to prevent it from being distracted and proceeding in a straight-forward pathway.

\section{References}

Adamson, G. (2007). Thinking Through Craft. UK, Berg.

Bentz, V. M. and Shapiro, B. (1998). Mindful Inquiry in Social Research. Newbury Park, London, New Delhi: Sage Publications.

Buchanan, R. (1995). Rhetoric, Humanism, and Design. In R. Buchanan and V. Margolin, V. (Eds.), Discovering Design: Explorations in Design Studies. London: University of Chicago Press.

Cross, N. (1999). Natural Intelligence in Design. Design Studies, 20 (1), 25-39.

Hanh, T.N. (1991). The Miracle of Mindfulness London: Rider.

Kabat-Zinn, J. (1994). Wherever You Go There You Are New York: Hyperion.

Langer, E. J. (1989). Mindfulness. Massachusetts:_Perseus Books. 
| Langer, E. J. (1997). The Power of Mindful Learning_Reading, Massachusetts:_Perseus Books.

| Risatti, H. (2007). A Theory of Craft: Function and Aesthetic Expression. USA: The University of North Carolina Press.

Sennett, R. (2008). The Craftsman. Great Britain: Allen Lane

Valentine, L. (2001). Visual Thinking: an observational tool for group inquiry. In M. Ivey, $(\mathrm{Ed}$.), Exploring the Interface between Education and the Creative Industries. Glasgow: The Lighthouse.

Valentine, L. (2004). The Activity of Rhetoric within the Process of a Designer's Thinking. Unpublished doctoral thesis, University of Dundee, Scotland.

Valentine, L. and Ivey, M. (2009). Sustaining Ambiguity and Fostering Openness in the (Design) Learning Environment. Journal of Art, Design and Communication in Higher Education, 7(3), 155-175.

\section{Author Biography}

\section{Louise Valentine}

Dr Louise Valentine is a researcher leading the major Arts and Humanities Research Council project 'Past, Present and Future Craft Practice' with Professor Georgina Follett. She is a lecturer at Duncan of Jordanstone College of Art and Design, a fellow of the Royal Society of the Arts and an Executive Member of the European Academy of Design.

\section{Georgina Follett}

Professor Georgina Follett is a Deputy Principal of the University of Dundee and Dean of Duncan of Jordanstone College of Art and Design, Dundee. She is also Principal Investigator of the 'Past, Present and Future Craft Practice', Arts and Humanities Research Council funded project. Georgina is a contemporary visual craft practitioner of 40 years, specialising in plique-à-jour enamelling. Her work is held in many private collections as well as the permanent and Roy Strong collections in the Victoria and Albert Museum, London. 